Supplement of Hydrol. Earth Syst. Sci., 24, 6059-6073, 2020

https://doi.org/10.5194/hess-24-6059-2020-supplement

(c) Author(s) 2020. This work is distributed under

the Creative Commons Attribution 4.0 License.

(c) (1)

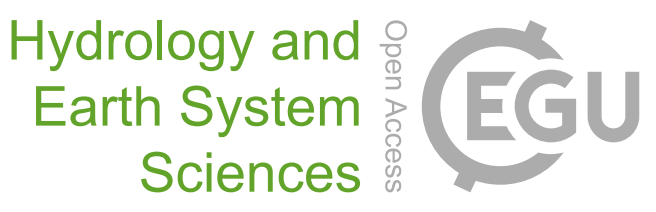

Supplement of

\title{
Assessing the value of seasonal hydrological forecasts for improving water resource management: insights from a pilot application in the UK
}

Andres Peñuela et al.

Correspondence to: Andres Peñuela (andres.penuela-fernandez@bristol.ac.uk)

The copyright of individual parts of the supplement might differ from the CC BY 4.0 License. 


\section{Reservoir system model}

We use weekly resolution to simulate the system and its operation for both the benchmark and the real-time optimization system (RTOS) approaches. For each reservoir (S1 and S2), the volume of stored water $(s(t+1))$ is equal to the previous week's storage $(s(t))$ plus natural and controlled inflows minus releases, evaporation and spills. The mass balance equations are:

S1: $s_{t+1}=s_{t}+\left(I_{S 1, t}+u_{R, S 1, t}\right)-\left(u_{S 1, D, t}+u_{S 1, R, t}+\right.$ evap $_{t}+$ spill $\left._{t}+e n v_{t}\right)$

S2: $s_{t+1}=s_{t}+\left(I_{S 2, t}\right)-\left(u_{S 2, D, t}+\operatorname{evap}_{t}+\right.$ spill $\left._{t}+e n v_{t}\right)$

Spills are calculated by imposing the hard constraint that the storage at next time-step should never exceed the reservoir capacity, hence they are either equal to zero or to the excess volume generated by the storage plus inflows minus outflows:

S1: $\operatorname{spill}_{t}=\max \left(s_{t}+\left(I_{S 1, t}+u_{R, S 1, t}\right)-\left(u_{S 1, D, t}+u_{S 1, R, t}+\operatorname{evap}_{t}+e n v_{t}\right)-s_{\max }, 0\right)$

S2: $\operatorname{spill}_{t}=\max \left(s_{t}+\left(I_{S 1, t}\right)-\left(u_{S 2, D, t}+\operatorname{evap}_{t}+e n v_{t}\right)-s_{\text {max }}, 0\right)$

where $s_{\max }$ the reservoir storage capacity in $\mathrm{m}^{3}$. Controlled inflows and outflows (u) are limited by the real-world system capacity. Besides, pumped inflows are limited such that flow downstream of R does not drop below a legal constraining value, unless using water released from S1. Evaporation fluxes (evap) are computed as the product of the reservoir surface area by the potential evaporation rate. Environmental compensation flows (env) are given by prescribed values that are kept constant over the year.

\section{Formulation of the optimization problem}

Both the release scheduling of the benchmark approach and the release and pumped inflow scheduling of the real-time optimization system (RTOS) approach are optimized using the NSGA2 genetic optimization algorithm included in the Platypus Python package (https://platypus.readthedocs.io/). In the RTOS, the optimization decision variables are both the weekly reservoir releases ( $\mathrm{u}_{\mathrm{S} 1, \mathrm{D}}$ and $\left.\mathrm{u}_{\mathrm{S} 2, \mathrm{D}}\right)$ and the weekly pumped inflows $\left(\mathrm{u}_{\mathrm{S} 1, \mathrm{R}}\right)$; in the benchmark operation, the decision variables are the reservoir releases only, while the pumped inflows are calculated according to the control curve. We assume that the future water demand is perfectly known in advance, and equal to the sum of the observed releases from $\mathrm{S} 1\left(\mathrm{u}_{\mathrm{S} 1, \mathrm{D}}\right)$ and $\mathrm{S} 2\left(\mathrm{u}_{\mathrm{S} 2, \mathrm{D}}\right)$ for the period of study. Unless physically unfeasible, the sum of reservoir releases $\left(u_{S 1, D}+u_{S 2, D}\right)$ is always forced to meet such demand.

When simulating the benchmark operation, the optimization is constrained to achieve maximum storage for both reservoirs (S1 and S2) by the end of the pumping license period window (1 April). The (single) optimisation objective is to minimize the sum of the energy costs for pumped release $\left(\mathrm{u}_{\mathrm{S} 1, \mathrm{D}}\right)$ and pumped storage $\left(\mathrm{u}_{\mathrm{R}, \mathrm{S} 1}\right)$ :

$$
\sum_{t=1}^{T} c_{R, S 1} u_{R, S 1, t}+\sum_{t=1}^{T} c_{S 1, D} u_{S 1, D, t}
$$


where $c$ is the pumping energy cost and $\mathrm{T}$ is the lead time in weeks.

For the RTOS approach, the optimization decision variables are the weekly reservoir releases $\left(\mathrm{u}_{\mathrm{S} 1, \mathrm{D}}\right.$ and $\left.\mathrm{u}_{\mathrm{S} 2, \mathrm{D}}\right)$ and the weekly pumped inflows $\left(\mathrm{u}_{\mathrm{S} 1, \mathrm{R}}\right)$ and the optimization objectives to be minimized are two:

1) Sum of the pumping energy costs (same equation as above)

2) Average difference between the reservoir capacity and storage volume by 1 April in the two reservoirs (S1 and S2):

$$
\frac{1}{M} \sum_{m=1}^{M} \frac{\left(s_{S 1, \max }-s_{S 1, T, m}\right)+\left(s_{S 2, \max }-s_{S 2, T, m}\right)}{2}
$$

where $s_{\max }$ is the reservoir storage capacity in $\mathrm{m}^{3}, s$ is the reservoir storage volume in $\mathrm{m}^{3}, T$ is the final week of the optimisation period, and $M$ the total number of ensemble members. Notice that, as denoted by the subscript $m$, the final storage of S1 and S2 will differ depending on the inflow forecast ensemble member that is used to force the simulation, even if the set of pumping and release decisions remain the same. Hence, at each iteration of the optimisation procedure, the same set of decisions is evaluated against each ensemble member and then the objective value is obtained by averaging across all the simulations (with the exception of the "deterministic" case presented in Sec. 3.2.2, where the ensemble forecast is replaced by the mean forecast and therefore averaging is not needed as only one simulation is run against any set of decisions).

For both operation approaches, benchmark and RTOS, the population size for the multi-objective optimization of the RTOS approach was 20. Notice that the method used here to handle ensemble forecasts (evaluate decision variables against each ensemble member separately, and then take the mean value of the objective functions) is sub-optimal with respect to more sophisticate methods (such as multi-stage stochastic programming, see Housh et al. (2013) or Raso et al. (2014)) that exploit the recursive nature of the decision problem within the optimisation period $(1, \mathrm{~T})$. Given the relatively low forecast skill and large uncertainty in this case study, we believe that the performance gains yielded by a more sophisticate optimisation method are likely to be modest. We thus preferred to adopt a simpler approach that ensures low computational cost and scales more easily to problems with multiple decision and state variables.

\section{Observational hydrological data}

Daily rainfall in the study area from 1981 to 2016 was derived from the UK Centre for Ecology and Hydrology (CEH) Gridded Estimates of Areal Rainfall (CEH-GEAR) dataset (Tanguy et al., 2014) and daily temperature and PET data for the period was derived from the CEH Gridded CEH-CHESS dataset (Robinson et al., 2016, 2017). CEH-GEAR is a gridded 1km product derived from the interpolation of observed rainfall across all daily and monthly rain gauges in the UK. CEH-CHESS is a gridded $1 \mathrm{~km}$ product derived from the Met Office 40km gridded MORECS dataset (Hough and Jones, 1997). We used the HBV model forced by observed weather data to simulate a proxy of the daily observed inflows (Figure 1). The HBV model was previously calibrated against observed hydrographs from 1972 to 2003 in the Wimbleball catchment. For the Wimbleball catchment the average observed yearly inflow is $24,462,227 \mathrm{~m}^{3} / \mathrm{year}$ with an interannual standard deviation equal to 4,340,594 
$\mathrm{m}^{3} /$ year. Given the lack of good calibration data for the Clatworthy catchment, we applied the Wimbleball parameter set to the Clatworthy catchment, given that they are adjacent to each-other. The averaged mean error from 1972 to 2004 of the Wimbleball calibrated inflow is $33,283 \mathrm{~m}^{3} / \mathrm{month}$ (from 1 Nov to $1 \mathrm{Apr}$ ).

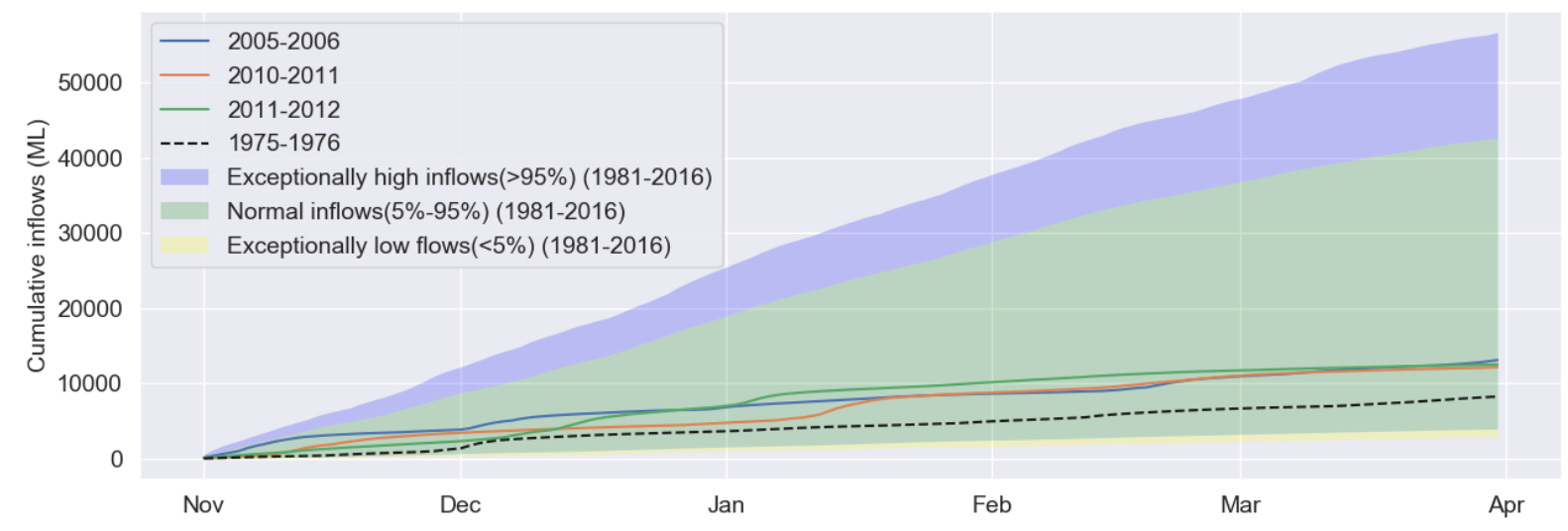

Figure S1 Cumulative inflows to the S1 reservoir in the worst-case scenario (1975-1976) and in the three driest years (2005-2006, 2010-2011 and 2011-2012) of the period used for the simulation of the RTOS (2005-2016). Only data relative to the pumping licence window (Nov to Apr) are shown. Shaded areas show the weekly inflow distribution calculated on the period used for the forecast bias correction of the meteorological forcing and ESP generation (1981-2016). Notice that the three driest years are relatively close to the worst-case scenario (1975-1976).

\section{References}

Hough, M. N., and Jones, R. J. A.: The United Kingdom Meteorological Office rainfall and evaporation calculation system: MORECS version 2.0-an overview, Hydrol. Earth Syst. Sci., 1, 227-239, 10.5194/hess-1-227-1997, 1997.

Housh, M., Ostfeld, A., and Shamir, U.: Limited multi-stage stochastic programming for managing water supply systems, Environmental Modelling \& Software, 41, 53-64, https://doi.org/10.1016/j.envsoft.2012.11.006, 2013.

Raso, L., Schwanenberg, D., van de Giesen, N. C., and van Overloop, P. J.: Short-term optimal operation of water systems using ensemble forecasts, Advances in Water Resources, 71, 200-208, https://doi.org/10.1016/j.advwatres.2014.06.009, 2014.

Robinson, E., Blyth, E., Clark, D., Comyn-Platt, E., Finch, J., and Rudd, A.: Climate hydrology and ecology research support system potential evapotranspiration dataset for Great Britain (1961-2015)[CHESS-PE], 2016.

Robinson, E., Blyth, E., Clark, D., Comyn-Platt, E., Finch, J., and Rudd, A.: Climate hydrology and ecology research support system meteorology dataset for Great Britain (1961-2015)[CHESS-met] v1. 2, 2017.

Tanguy, M., Dixon, H., Prosdocimi, I., Morris, D. G., and Keller, V. D. J.: Gridded estimates of daily and monthly areal rainfall for the United Kingdom (1890-2012) [CEH-GEAR], in, NERC Environmental Information Data Centre, 2014. 